\title{
Addiction-Prone Lewis But Not Fischer Rats Develop Compulsive Running that Coincides with Downregulation of Nerve Growth Factor Inducible-B and Neuron-Derived Orphan Receptor 1
}

\author{
Martin Werme, ${ }^{1}$ Peter Thorén, ${ }^{2}$ Lars Olson, ${ }^{1}$ and Stefan Brené ${ }^{1}$ \\ Departments of ${ }^{1}$ Neuroscience and ${ }^{2}$ Physiology and Pharmacology, Karolinska Institutet, S-171 77 Stockholm, Sweden
}

We have examined the effects of chronic voluntary running for $30 \mathrm{~d}$ on the levels of nerve growth factor inducilble-B (NGFI-B) and neuron-derived orphan receptor 1 (NOR1) mRNAs in Fischer and Lewis rats. The aim was to compare the addictionprone Lewis rat strain to the Fischer strain in a plausible model for natural reward. The Lewis strain ran markedly more than the Fischer strain, as indicated by the length of running per day when given free access to running wheels. Both strains progressively increased their amount of daily running. By day 14, Lewis rats had reached a maximal level corresponding to 10 $\mathrm{km} / \mathrm{d}$, which slowly decreased to $\sim 8 \mathrm{~km} / \mathrm{d}$. Fischer rats ran considerably less, averaging $\sim 1.5 \mathrm{~km} / \mathrm{d}$ by day 30 . After $30 \mathrm{~d}$ of running, levels of mRNA encoding NGFI-B and Nor1 were decreased in cerebral cortex in Lewis but not Fischer rats. The

Animal models comparing inbred rat strains are often used in studies characterizing genetic factors in addiction and stress (George and Goldberg, 1989; Nestler, 1992). The Lewis rat has a higher preference to self-administer or to develop place preference for cocaine, morphine, ethanol, and nicotine compared with the Fischer rat (Suzuki et al., 1988a,b; Kosten et al., 1994; Horan et al., 1997). Fischer and Lewis rats are inbred from the Sprague Dawley rat, and drug-naive Lewis rats display many features in the mesolimbic dopamine pathway that are similar to those of addicted or chronically stressed Sprague Dawley rats (Nestler, 1992). Fischer rats have higher basal levels of corticosterone than Lewis rats (Dhabhar et al., 1993; Ortiz et al., 1995). In addition, stress leads to higher sustained levels of corticosterone in Fischer than in Lewis rats (Dhabhar et al., 1993; Ortiz et al., 1995; Gomez et al., 1996). Overall, the Fischer rat is more sensitive to stress then the Lewis rat.

Nerve growth factor inducible-B (NGFI-B), neuron-derived ophan receptor 1 (NOR1), and nur(77)-related 1 (Nurr1) belong to a family of nuclear orphan receptors with unknown ligands (Mangelsdorf et al., 1995). They are expressed within the mesolimbic and mesostriatal dopamine system, which is functionally involved in drug addiction, Parkinson's disease, and schizophre-

Received Feb. 2, 1999; revised April 29, 1999; accepted May 4, 1999.

This work was supported by the Swedish MRC (03185, 11642, and 04764), Thurings and Kapten Erikssons stiftelse, Centrum för idrottsforskning (CIF 89/98), AMF, AFA, and United States Public Health Service grants. S.B. was supported by a fellowship from the Swedish Brain Foundation. We thank Eva Lindqvist for technical assistance, Dr. Rolf Zetterström for valuable discussions, and Ida Engqvist for editorial assistance.

Correspondence should be addressed to Dr. Stefan Brené, Department of Neuroscience, Karolinska Institutet, S-171 77 Stockholm, Sweden.

Copyright (C) 1999 Society for Neuroscience $0270-6474 / 99 / 196169-06 \$ 05.00 / 0$ downregulation of NGFI-B mRNA in Lewis rats could not be attenuated by the opioid receptor antagonist naloxone. Instead, naloxone by itself downregulated NGFI-B in striatum and cerebral cortex in both strains. In contrast, naloxone had no effect on Nor1 mRNA levels, although the running-induced downregulation of Nor1 was, in most cases, attenuated by naloxone. Data from the present study suggest that the same genetic factors contributing to the drug addiction-prone behavior of Lewis rats also control the excessive running behavior and that this coincides with downregulation of transcription factors of the NGFI-B family.

Key words: abuse; basal ganglia; in situ hybridization; exercise; stress; withdrawal; NR4A1; NR4A2; NR4A3

nia. NGFI-B and Nor1 are expressed under basal conditions in accumbens and striatum (Zetterström et al., 1996a,b), whereas Nurr1 is expressed in dopaminergic neurons and also has a role in dopamine neurogenesis (Zetterström et al., 1997). NGFI-B is induced in hypothalamus after chronic and acute stress (Chan et al., 1993; Rivest and Rivier, 1994). NGFI-B and glucocorticoids have opposite actions on the regulation of the proopiomelanocortin gene in the pituitary (Drouin et al., 1998). NGFI-B mRNA levels are also activated by ethanol (Ogilvie et al., 1998), caffeine (Svenningsson et al., 1995), ischemia (Lin et al., 1996), and dopamine D2 receptor agonists (Svenningsson and Fredholm, 1997).

Physical activity is assumed to maintain and enhance physical and mental health. Long-term regular exercise in human subjects is reported to increase self-esteem and relieve anxiety (Bahrke, 1979; Greist et al., 1979; Sonstroem and Morgan, 1989). In spontaneously hypertensive rats, CSF $\beta$-endorphin levels are increased by voluntary chronic running and remain high for the first $2 \mathrm{~d}$ after interruption of running, after which they decrease (Hoffmann et al., 1990b). This decrease coincides with increased aggressive behavior, and is thus possibly caused by cessation of chronic running and the consequent endorphin withdrawal (Hoffmann et al., 1987, 1990b).

Our aim was to investigate whether inbred rat strains that differ in response to addictive drugs and stress also differ in running behavior. We show that the drug-preferring Lewis rat strain also has a higher preference for excessive running. In addition, we demonstrate that compulsive chronic running downregulates mRNA encoding the transcription factors NGFI-B and Nor1. Our findings implicate a role for NGFI-B and Nor1 in neural circuits associated with addiction and stress. 


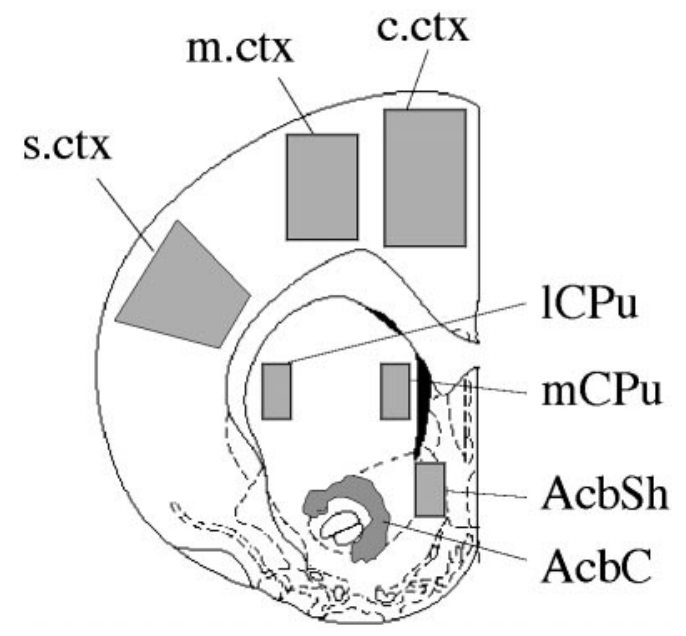

Figure 1. Quantitative computerized image analysis was performed over the indicated shaded areas. Analysis was performed at approximately the level of bregma $1.60 \mathrm{~mm}$ [figure modified from plate 12 in Paxinos and Watson (1997)]. $l C P u$, Lateral caudate putamen; $m C P u$, medial caudate putamen; $A c b S h$, accumbens shell; $A c b C$, accumbens core; $c . c t x$, cingulate cortex; m.ctx, motor cortex; s.ctx, sensory cortex.

\section{MATERIALS AND METHODS}

Male Fischer 344 and Lewis 250 gm rats (Møllegaard Breeding Center, Skensved, Denmark) with access to food and water ad libitum were housed in individual cages. Those animals having access to running wheels (diameter, $34 \mathrm{~cm}$; one revolution corresponding to $1.07 \mathrm{~m}$ ) had unlimited access. The running behavior of each animal was recorded using a computer-based data collection system. Naloxone $(2 \mathrm{mg} / \mathrm{kg}$, s.c.) was administered $2 \mathrm{hr}$ before dissection of the animals. Because most running behavior occurred during nighttime and because rats were dissected between 12:00 P.M. and 1:30 P.M., they were not dissected at the time of active running.

In situ hybridization. Animals were killed, and brains were frozen on dry ice. The protocol for in situ hybridization was according to Dagerlind et al. (1992). Coronal brain sections $(14 \mu \mathrm{m})$ were cut on a cryostat at $-20^{\circ} \mathrm{C}$. The sections were thawed onto glass slides. The hybridization cocktail contained $50 \%$ formamide, $4 \times \mathrm{SSC}(1 \times \mathrm{SSC}$ is $0.15 \mathrm{M} \mathrm{NaCl}$ and 0.015 sodium citrate, $\mathrm{pH} 7.0), 1 \times$ Denhardt's solution, $1 \%$ Sarcosyl, 0.02 $\mathrm{M} \mathrm{Na}_{3} \mathrm{PO}_{4}, \mathrm{pH} 7.0,10 \%$ dextran sulphate, $0.06 \mathrm{~m} \mathrm{DTT}$, and $0.1 \mathrm{mg} / \mathrm{ml}$ sheared salmon sperm DNA. For detection of NGFI-B, (1191-1238) (Milbrandt, 1988), Nurr1 (1430-1477) (Law et al., 1992), and Nor1 (1191-1238) (Ohkura et al., 1994) mRNAs, 48-mer oligonucleotides complementary to described nucleotides were used. The oligonucleotide probes were $3^{\prime}$-end labeled with $\alpha-{ }^{35}$ S-dATP (DuPont NEN, Wilmington, DE) using terminal deoxynucleotidyl transferase (Life Technologies, Gaithersburg, MD) to a specific activity of $\sim 1 \times 10^{9} \mathrm{cpm} / \mathrm{mg}$. The labeled probe was then separated from unincorporated nucleotides (Nensorb-20 column; DuPont NEN), and $5 \times 10^{6} \mathrm{cpm}$ of probe was added per milliliter of hybridization cocktail. Each section was incubated with $0.1 \mathrm{ml}$ of the hybridization cocktail. Hybridization was performed for $18 \mathrm{hr}$ in a humidified chamber at $42^{\circ} \mathrm{C}$. After hybridization, sections were rinsed four times for $20 \mathrm{~min}$ each in $1 \times \mathrm{SSC}$ at $60^{\circ} \mathrm{C}$. Finally, sections were rinsed in autoclaved water for $10 \mathrm{sec}$, dehydrated in alcohol, and air dried. Thereafter, the slides were exposed to film (Hyperfilm; Amersham, Arlington Heights, IL) for 1-3 weeks.

Image analysis. Optical density values from in situ hybridizations were quantified on a computerized image analysis system (NIH Image analysis program, version 1.62). Measurements were performed in the shaded areas covering the indicated brain regions in Figure 1. To correlate optical density values on the autoradiograms to amount of radioactivity (nanoCuries per gram) corresponding to ${ }^{35} \mathrm{~S}$-labeled mRNAs, a ${ }^{14} \mathrm{C}$ step standard (Amersham) was used.

Statistical procedures. Data were analyzed using a two-way ANOVA (Statistica, version 4.1 for Macintosh; StatSoft, Inc., Tulsa, OK) with repeated measurements in seven different areas to examine strain and treatment differences.

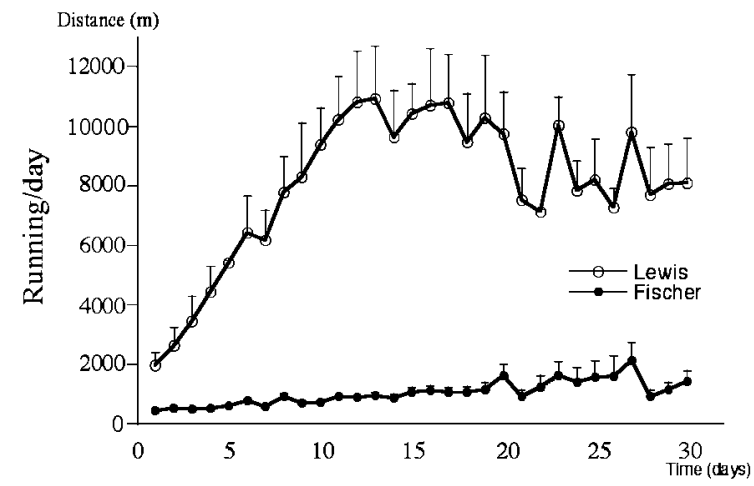

Figure 2. Running behavior in running wheels. Lewis and Fischer rats were individually housed and had free access to running wheels for $30 \mathrm{~d}$. Activity in the wheels is converted to meters. The rats were mostly active during nights. Values are means $\pm \operatorname{SEM}(n=8)$.

\section{RESULTS}

\section{Running behavior}

During the first $24 \mathrm{hr}$ that naive Lewis rats used running wheels, distances corresponding to $\sim 2000 \mathrm{~m}$ were achieved (Fig. 2). They increased their daily running until day 13-14 when they averaged $\sim 10,000 \mathrm{~m} / \mathrm{d}$ (Fig. 2). Running behavior stabilized at a high level from approximately day 13 until day 21 . There was consequently a trend of decreasing daily running distance until day 30 when the experiment ended. Naive Fischer rats ran only $\sim 400 \mathrm{~m}$ during the first $24 \mathrm{hr}$ (Fig. 2). They then gradually increased their daily running, and by the last day of the experiment (day 30), they ran $\sim 1500 \mathrm{~m}$.

\section{Naloxone treatment}

To analyze whether the high levels of endogenous opioids noted in chronic running (Hoffmann et al., 1990b) could cause physical dependence, the opioid receptor antagonist naloxone $(2 \mathrm{mg} / \mathrm{kg}$, s.c.) was administered to possibly precipitate physical withdrawal symptoms similar to those after chronic morphine administration. However, no increased signs of seizures, diarrhea, rearing, or loss of body weight were detected (data not shown). Therefore, we cannot conclude from our experiments that the rats developed physical dependence based on the increased production of endogenous opioids.

\section{Basal levels of NGFI-B, Nor1, and Nurr1 mRNA in rats housed individually for 3 weeks without access to running wheel}

Similar basal levels of NGFI-B mRNA were detected in all analyzed regions in Fischer and Lewis rats (Fig. $3 A$ ). In Lewis rats, a higher basal level of Nor1 mRNA was detected in cingulate and motor cortex (Figs. 3B, 4). In the other regions analyzed, no differences in Nor1 mRNA were detected. Nurr1 mRNA was detected at similar levels in claustrum in the two rat strains (data not shown).

\section{NGFI-B, Nor1, and Nurr1 mRNA expression after chronic running}

In Lewis rats, chronic running downregulated NGFI-B mRNA levels in cingulate, motor, and sensory cortex and downregulated 
A
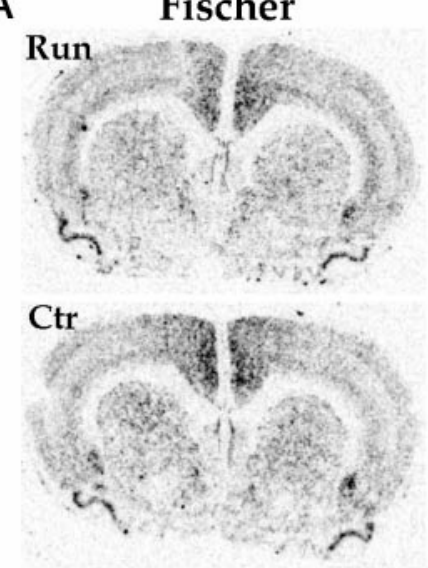

B
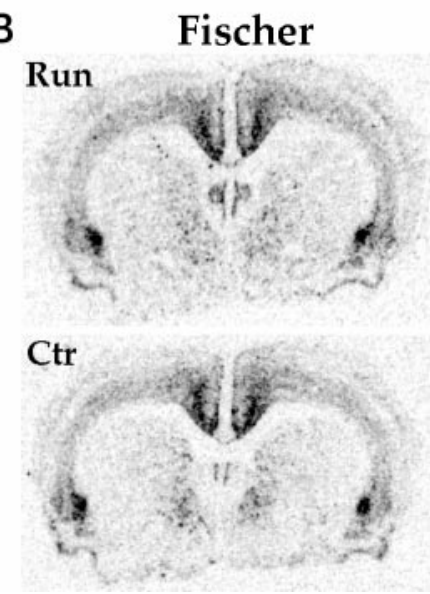

Lewis
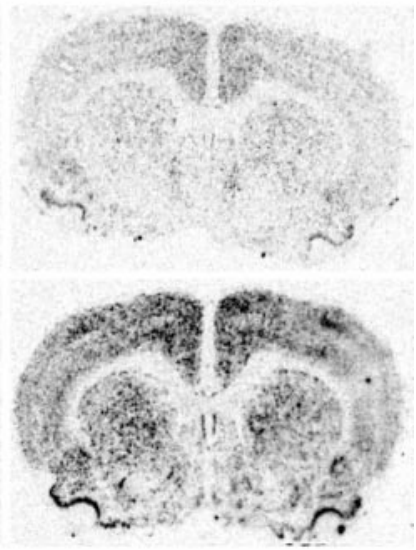

Lewis
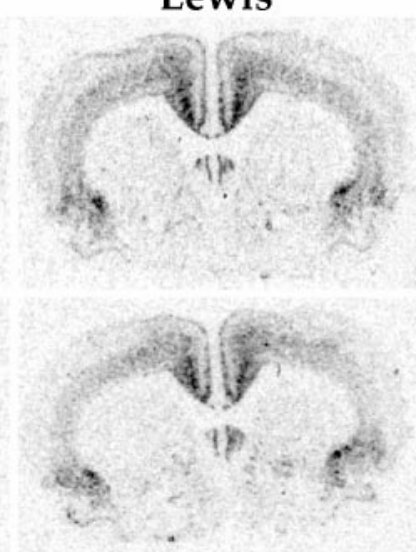

Figure 3. Film autoradiograms after in situ hybridization using 48-mer oligonucleotide DNA probes to detect mRNA distribution and regulation of NFGI-B $(A)$ and Nor1 $(B)$ mRNA levels in rats that were individually housed and had free access to running wheels for $30 \mathrm{~d}$. Control rats were individually housed for $30 \mathrm{~d}$ without access to running wheels.

Nor1 mRNA in accumbens shell and core, cingulate, and motor cortex (Figs. $3 A, B, 4$ ). In forelimb regions of somatosensory cortex that had received chronic sensory stimulation, similar downregulation of NGFI-B and Nor1 mRNAs could not be detected (data not shown), as demonstrated at the level of sensory cortex as defined in Figure 1. In all other regions analyzed for both NGFI-B and Nor1 message, there were trends of downregulation. In Fischer rats, running had no effect on the levels of NGFI-B or Nor1 mRNA (Figs. $3 A, B, 4)$. Running had no effect on Nurr1 mRNA in analyzed regions in either rat strain (data not shown).

\section{NGFI-B, Nor1, and Nurr1 mRNA expression after chronic running and naloxone}

Naloxone administration alone did not alter Nor1 mRNA levels in Lewis or Fischer rats (Fig. 5). In contrast, naloxone downregulated NGFI-B mRNA in a similar manner in the medial caudate putamen and cingulate cortex in both Fischer and Lewis rats (Fig. 5 ). In addition, naloxone downregulated NGFI-B mRNA in lateral caudate putamen, sensory, and motor cortex in the Lewis rat (Fig. 5). Naloxone had no effect on Nurr1 mRNA (data not shown). In Lewis rats, the running-induced downregulation of
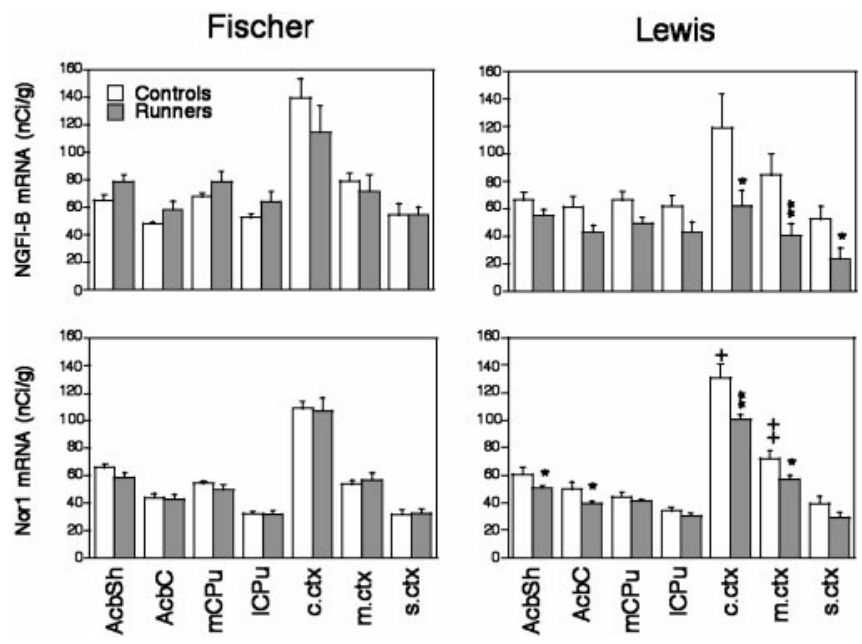

Figure 4. Relative levels of NGFI-B and Nor1 mRNA in control rats that were individually housed for $30 \mathrm{~d}$ without access to running wheels and compared with runners with access to running wheels. For abbreviations, see Figure 1. Values are means $\pm \operatorname{SEM}(n=8) .+p<0.05 ;++p<0.01$, significance for higher basal level in the indicated strain; * $p<0.05$; ** $p<$ 0.01 , indicates significantly lower levels of the respective mRNA after running.
Fischer
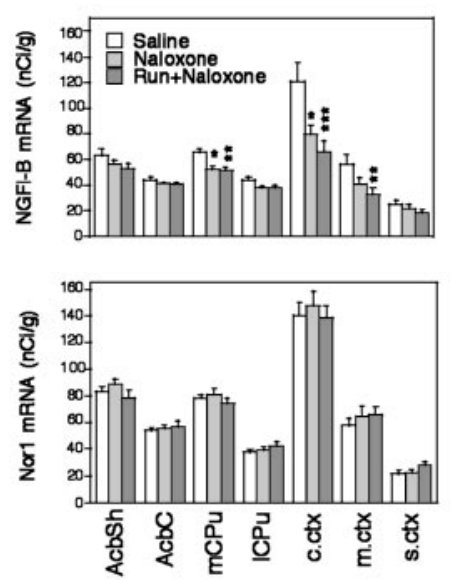

Lewis
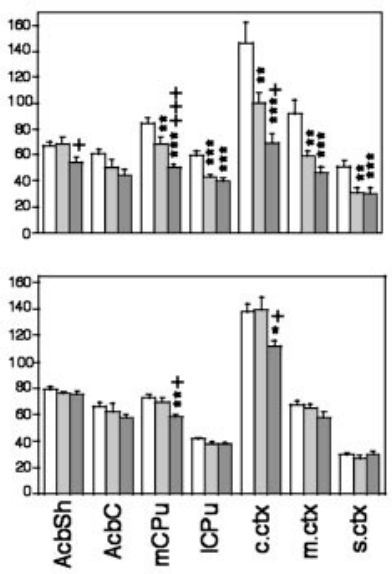

Figure 5. Relative levels of NGFI-B and Nor1 mRNA in saline-injected control animals (Saline) without access to running wheels, naloxonetreated $(2 \mathrm{mg} / \mathrm{kg}$, s.c) rats with (Running + Naloxone) and without (Naloxone) free access to running. The animals were killed $2 \mathrm{hr}$ after injections. For abbreviations, see Figure 1. Values are means $\pm \operatorname{SEM}(n=$ $6-8) .{ }^{*} p<0.05 ;{ }^{* *} p<0.01 ; * * *<0.001$, indicates significant difference when comparing saline-injected control animals with naloxone-treated animals or animals with access to running wheels and naloxone. $+p<$ $0.05 ;++p<0.01 ;+++p<0.001$, indicates significant differences when comparing naloxone treated animals without access to running wheels with animals receiving naloxone with access to running wheels.

Nor1 mRNA was blocked by naloxone in the accumbens shell and core and motor cortex (Figs. 4, 5). Naloxone did not modify the running-induced changes in NGFI-B mRNA in any analyzed region (Figs. 4, 5). The relative downregulation of NGFI-B in all regions in the group of animals with free wheel access and given naloxone was in the range of the downregulation observed by running alone (Figs. 4, 5). It therefore appears that naloxone downregulation and running downregulation are not synergistic in terms of regulating NGFI-B levels. 


\section{DISCUSSION}

In the present study, we have analyzed running behavior and regulation of mRNA encoding the nuclear orphan receptors NGFI-B and Nor1 in two rat strains with known differences in their stress responses and preferences for addictive behavior. The Lewis rats covered significantly longer daily running distances compared with the Fischer rats. As soon as the first day with free access to running wheels, Lewis rats ran markedly longer than Fischer rats. Lewis rats displayed an almost linear increase of running distance the first $14 \mathrm{~d}$, after which they reached a plateau at which they remained or from which they decreased slightly. In contrast, Fischer rats did not seem to reach a plateau during the $30 \mathrm{~d}$ trial period. Instead, they increased their daily running distance throughout the experiment.

One reason for the discrepancy in running behavior could be that long-distance running might activate endogenous opioid systems and thus indirectly activate the same central monoamine pathways in the brain as those stimulated by drugs of abuse. Because Lewis rats more readily initiate a drug administrative behavior (Nestler, 1992), it is possible that the rewarding effects are greater in this rat strain. Rewarding effects of morphine are suggested to be mediated via activation of dopaminergic cells in the ventral tegmental area (VTA) leading to release of dopamine in nucleus accumbens. One mechanism for this could be a $\mu$-receptor disinhibition mechanism via GABAergic interneurons, which under normal conditions blocks activity of dopaminergic cells in the VTA (Johnson and North, 1992). $\beta$-endorphins function as endogenous agonists for opioid $\mu$ receptors, and it is possible that $\beta$-endorphins could also activate dopaminergic neurons in the VTA via a mechanism similar to that of morphine. By analogy, it could be more rewarding for Lewis rats to run than for Fischer rats, which would explain the behavior results in our experiments.

Another possible explanation for the different running patterns in Lewis versus Fischer rats might be differences in stress sensitivity or spontaneous locomotor activity. However, when placed in activity cages or during open-field tests, Fischer rats display more locomotor activity than the Lewis rats (Chaouloff et al., 1995). In our experiments using running wheels, Lewis rats ran considerably more than Fischer rats as soon as during the first 24 $\mathrm{hr}$, and in the light of spontaneous locomotor data, it appears as if the higher running levels in Lewis rats cannot be attributed to higher spontaneous locomotor activity.

Chronic voluntary running was associated with a statistically significant decrease of NGFI-B mRNA in cingulate, motor, and sensory cortex and a trend toward a downregulation in the other regions analyzed in the Lewis rat. Nor1 was also downregulated with statistical significance in accumbens core and shell, as well as cingulate and motor cortex, with a trend toward downregulation in the other investigated brain regions in the Lewis rat. In the Fischer rat, running had no effect in any analyzed brain region. In other studies, social stress has been reported to be associated with increased levels of c-fos in cortex cinguli and amygdala (KollackWalker et al., 1997). c-fos and NGFI-B are co-induced in hypothalamus in several models of stress (Umemoto et al., 1997; Ogilvie et al., 1998). Rats are nocturnal animals, and it is possible that the decreased levels of NGFI-B and Nor1 messages in cerebral cortex, accumbens, and caudate putamen in the running Lewis rat might reflect a state of decreased functional activity at the time of dissection (12:00 P.M.) in brain regions involved in stress responses, motor function, and reward. It is possible that these brain regions had been adapted to a state of high activity during chronic running and that the lower levels of NGFI-B and Nor1 detected could reflect an adaptation to this. In contrast, in the Fischer rats, which do not develop the same excessive running behavior, no such downregulation of NGFI-B or Nor1 was observed. It is, however, important to note that the animals in our study were dissected after continuous free access to running wheels and that the dissection was performed during their resting phase of the day. At this time, the CSF endorphin levels are still increased (Hoffmann et al., 1990b), and consequently the animals cannot be regarded as experiencing an endorphin withdrawal state. In fact, endorphin levels are maintained at a high level for $48 \mathrm{hr}$ after blocking access to running wheels (Hoffmann et al., 1990b).

Chronic administration of morphine causes physical dependence, and by blocking $\mu$-receptors, the opioid receptor antagonist naloxone precipitates a withdrawal that is manifested by diarrhea, seizures, and weight loss. To analyze $\mu$-receptormediated effects in our model, we administered naloxone at a dose that blocks increase of pain thresholds after chronic running (Shyu et al., 1982) but not the $\kappa$-mediated effects on blood pressure after rhythmic muscle activation (Hoffmann et al., 1990a). However, we could not detect any obvious signs of physical withdrawal. The downregulation of Nor1 mRNA caused by running was in some instances attenuated by naloxone, whereas naloxone did not modulate the running-induced NGFI-B downregulation. Instead, naloxone alone downregulated NGFI-B in medial and lateral striatum, as well as in cortex cinguli, in both Fischer and Lewis rats. The effects of naloxone suggest that the running-induced downregulation of NGFI-B is not acutely mediated via endogenous opioids, whereas endogenous opioids might contribute to the regulation of Nor1 mRNA.

Acute treadmill activity increases extracellular dopamine levels in nucleus accumbens in the rat (Wilson and Marsden, 1995). Chronic running increases CSF $\beta$-endorphins (Hoffmann et al., 1990b) and modulates turnover of central brain monoamines (Elam et al., 1987) involved in brain mechanisms of stress, as well as psychiatric conditions of drug addiction and affective disorders. In spontaneously hypertensive rats, chronic running leads to both less aggressive behavior and decreased hyperexplorative behavior (Hoffmann et al., 1987). Dopamine is believed to be the mediator of central reward mechanisms via the dopaminergic cell group in the VTA, which projects to nucleus accumbens in the ventral forebrain (Koob, 1992; Nestler, 1992). In fact, most drugs that are abused by humans are also self-administered by rats, and it has been documented that acute administration of cocaine, amphetamine, morphine, nicotine, and ethanol all trigger release of dopamine in nucleus accumbens (Di Chiara and Imperato, 1988). In addition, we have demonstrated that compulsive running in Lewis rats and cocaine administration both increase levels of dynorphin mRNA in striatum, suggesting a common mechanism of regulation (our unpublished observations). Because chronic running modulates central dopamine levels, running could possibly also effect brain reward pathways.

Interestingly, after withdrawal from addictive drugs such as amphetamine, cocaine, opioids, nicotine, or ethanol, subjects suffer psychological symptoms such as depression and anxiety, which are believed to play a major role in motivation, for increased drug intake, and relapse (Koob and Le Moal, 1997). It is possible that the psychological features of withdrawal from addictive drugs have a common molecular and neurobiological background, ultimately allowing application of a common therapeutic program. Joggers frequently express positive mood changes (“joggers' 
high"), with reduced levels of depression and anxiety (Bahrke, 1979; Greist et al., 1979; Sonstroem and Morgan, 1989). In fact, exercise appears to be as efficient as antidepressant drug therapy for selected types of anxiety and depression (Bahrke, 1979; Greist et al., 1979; Sonstroem and Morgan, 1989). The documented changes caused by chronic running in animal models involve CSF $\beta$-endorphins and central monoamine turnover, which might underlie the beneficial sense of well being caused by running.

In this study, we show that the addiction-prone Lewis rat developed a higher preference for running compared with the less addiction-prone Fischer rat. We therefore speculate on common mechanisms in development of drug-addictive behavior and compulsive exercise. One hypothesis is that the Lewis rat by running activates the same neurobiological circuits as those activated by drugs of abuse. By continuing to run, the animal does not enter the psychological withdrawal phase associated with anxiety and depression. In fact, forced withdrawal from running in the spontaneous hypertensive rat leads to aggressive behavior that possibly could be similar to the psychological withdrawal from addictive drugs. In a first step to characterize the molecular background of the voluntary running behavior, we analyzed the levels of the nuclear orphan receptors NGFI-B and Nor1 mRNAs, which we found were both downregulated by chronic running. However, further studies are necessary to clarify the role of NGFI-B and Nor1 in these processes. We conclude that an addiction-prone rat strain develops compulsive running that is associated with a temporally related downregulation of important transcription factors of the NGFI-B family. Compulsive running and drug addiction may share certain, but not all, underlying molecular mechanisms.

\section{REFERENCES}

Bahrke MS (1979) Exercise, meditation and anxiety reduction: a review. Am Correct Ther J 33:41-44.

Chan RK, Brown ER, Ericsson A, Kovacs KJ, Sawchenko PE (1993) A comparison of two immediate-early genes, c-fos and NGFI-B, as markers for functional activation in stress-related neuroendocrine circuitry. J Neurosci 13:5126-5138.

Chaouloff F, Kulikov A, Sarrieau A, Castanon N, Mormede P (1995) Male Fischer 344 and Lewis rats display differences in locomotor reactivity, but not in anxiety-related behaviours: relationship with the hippocampal serotonergic system. Brain Res 693:169-178.

Dagerlind A, Friberg K, Bean AJ, Hökfelt T (1992) Sensitive mRNA detection using unfixed tissue: combined radioactive and nonradioactive in situ hybridization histochemistry. Histochemistry 98:39-49.

Dhabhar FS, McEwen BS, Spencer RL (1993) Stress response, adrenal steroid receptor levels and corticosteroid-binding globulin levels: a comparison between Sprague Dawley, Fischer 344 and Lewis rats. Brain Res 616:89-98.

Di Chiara G, Imperato A (1988) Drugs abused by humans preferentially increase synaptic dopamine concentrations in the mesolimbic system of freely moving rats. Proc Natl Acad Sci USA 85:5274-5278.

Drouin J, Maira M, Philips A (1998) Novel mechanism of action for Nur77 and antagonism by glucocorticoids: a convergent mechanism for CRH activation and glucocorticoid repression of POMC gene transcription. J Steroid Biochem Mol Biol 65:59-63.

Elam M, Svensson TH, Thorén P (1987) Brain monoamine metabolism is altered in rats following spontaneous long-distance running. Acta Physiol Scand 130:313-316.

George FR, Goldberg SR (1989) Genetic approaches to the analysis of addiction processes. Trends Pharmacol Sci 10:78-83.

Gomez F, Lahmame A, de Kloet ER, Armario A (1996) Hypothalamicpituitary-adrenal response to chronic stress in five inbred rat strains: differential responses are mainly located at the adrenocortical level. Neuroendocrinology 63:327-337.

Greist JH, Klein MH, Eischens RR, Faris J, Gurman AS, Morgan WP (1979) Running as treatment for depression. Compr Psychiatry 20:41-54.

Hoffmann P, Thorén P, Ely D (1987) Effect of voluntary exercise on open-field behavior and on aggression in the spontaneously hypertensive rat (SHR). Behav Neural Biol 47:346-355.

Hoffmann P, Delle M, Thorén P (1990a) Role of opioid receptors in the long-lasting blood pressure depression after electric muscle stimulation in the hind leg of the rat. Acta Physiol Scand 140:191-198.

Hoffmann P, Terenius L, Thorén P (1990b) Cerebrospinal fluid immunoreactive $\beta$-endorphin concentration is increased by voluntary exercise in the spontaneously hypertensive rat. Regul Pept 28:233-239.

Horan B, Smith M, Gardner EL, Lepore M, Ashby Jr CR (1997) (-)Nicotine produces conditioned place preference in Lewis, but not Fischer 344 rats. Synapse 26:93-94.

Johnson SW, North RA (1992) Opioids excite dopamine neurons by hyperpolarization of local interneurons. J Neurosci 12:483-488.

Kollack-Walker S, Watson SJ, Akil H (1997) Social stress in hamsters: defeat activates specific neurocircuits within the brain. J Neurosci 17:8842-8855.

Koob GF (1992) Drugs of abuse: anatomy, pharmacology and function of reward pathways. Trends Pharmacol Sci 13:177-184.

Koob GF, Le Moal M (1997) Drug abuse: hedonic homeostatic dysregulation. Science 278:52-58.

Kosten TA, Miserendino MJ, Chi S, Nestler EJ (1994) Fischer and Lewis rat strains show differential cocaine effects in conditioned place preference and behavioral sensitization but not in locomotor activity or conditioned taste aversion. J Pharmacol Exp Ther 269:137-144.

Law SW, Conneely OM, DeMayo FJ, O'Malley BW (1992) Identification of a new brain-specific transcription factor, NURR1. Mol Endocrinol 6:2129-2135.

Lin TN, Chen JJ, Wang SJ, Cheng JT, Chi SI, Shyu AB, Sun GY, Hsu CY (1996) Expression of NGFI-B mRNA in a rat focal cerebral ischemia-reperfusion model. Brain Res Mol Brain Res 43:149-156.

Mangelsdorf DJ, Thummel C, Beato M, Herrlich P, Schutz G, Umesono K, Blumberg B, Kastner P, Mark M, Chambon P, Evans RM (1995) The nuclear receptor superfamily: the second decade. Cell 83:835-839.

Milbrandt J (1988) Nerve growth factor induces a gene homologous to the glucocorticoid receptor gene. Neuron 1:183-188.

Nestler EJ (1992) Molecular mechanisms of drug addiction. J Neurosci 12:2439-2450.

Ogilvie KM, Lee S, Rivier C (1998) Divergence in the expression of molecular markers of neuronal activation in the parvocellular paraventricular nucleus of the hypothalamus evoked by alcohol administration via different routes. J Neurosci 18:4344-4352.

Ohkura N, Hijikuro M, Yamamoto A, Miki K (1994) Molecular cloning of a novel thyroid/steroid receptor superfamily gene from cultured rat neuronal cells. Biochem Biophys Res Commun 205:1959-1965.

Ortiz J, DeCaprio JL, Kosten TA, Nestler EJ (1995) Strain-selective effects of corticosterone on locomotor sensitization to cocaine and on levels of tyrosine hydroxylase and glucocorticoid receptor in the ventral tegmental area. Neuroscience 67:383-397.

Paxinos G, Watson C (1997) The rat brain in stereotaxic coordinates, Ed 3. Sydney: Academic.

Rivest S, Rivier C (1994) Stress and interleukin-1 $\beta$-induced activation of c-fos, NGFI-B and CRF gene expression in the hypothalamic PVN: comparison between Sprague Dawley, Fischer-344 and Lewis rats. J Neuroendocrinol 6:101-117.

Shyu BC, Andersson SA, Thorén P (1982) Endorphin mediated increase in pain threshold induced by long-lasting exercise in rats. Life Sci 30:833-840.

Sonstroem RJ, Morgan WP (1989) Exercise and self-esteem: rationale and model. Med Sci Sports Exercise 21:329-337.

Suzuki T, George FR, Meisch RA (1988a) Differential establishment and maintenance of oral ethanol reinforced behavior in Lewis and Fischer 344 inbred rat strains. J Pharmacol Exp Ther 245:164-170.

Suzuki T, Otani K, Koike Y, Misawa M (1988b) Genetic differences in preferences for morphine and codeine in Lewis and Fischer 344 inbred rat strains. Jpn J Pharmacol 47:425-431.

Svenningsson P, Fredholm BB (1997) Caffeine mimics the effect of a dopamine D2/3 receptor agonist on the expression of immediate early 
genes in globus pallidus. Neuropharmacology 36:1309-1317.

Svenningsson P, Nomikos GG, Fredholm BB (1995) Biphasic changes in locomotor behavior and in expression of mRNA for NGFI-A and NGFI-B in rat striatum following acute caffeine administration. J Neurosci 15:7612-7624.

Umemoto S, Kawai Y, Ueyama T, Senba E (1997) Chronic glucocorticoid administration as well as repeated stress affects the subsequent acute immobilization stress-induced expression of immediate early genes but not that of NGFI-A. Neuroscience 80:763-773.

Wilson WM, Marsden CA (1995) Extracellular dopamine in the nucleus accumbens of the rat during treadmill running. Acta Physiol Scand $155: 465-466$
Zetterström RH, Solomin L, Mitsiadis T, Olson L, Perlmann T (1996a) Retinoid X receptor heterodimerization and developmental expression distinguish the orphan nuclear receptors NGFI-B, Nurr1, and Nor1. Mol Endocrinol 10:1656-1666.

Zetterström RH, Williams R, Perlmann T, Olson L (1996b) Cellular expression of the immediate early transcription factors Nurr1 and NGFI-B suggests a gene regulatory role in several brain regions including the nigrostriatal dopamine system. Brain Res Mol Brain Res 41:111-120.

Zetterström RH, Solomin L, Jansson L, Hoffer BJ, Olson L, Perlmann T (1997) Dopamine neuron agenesis in Nurr1-deficient mice. Science 276:248-250 